\title{
PRÁTICAS INTEGRATIVAS DE CUIDADO EM SAÚDE NO CONTEXTO DO ENSINO MÉDIO: A EXPERIENCIA DA TERAPIA COMUNITÁRIA INTEGRATIVA - TCI
}

\author{
PRACTICAS INTEGRATIVAS DE ATENCIÓN DE SALUD EN EL CONTEXTO DE LA \\ ESCUELA SECUNDRIA: LA EXPERIENCIA DE LA TERAPIA COMUNITARIA \\ INTEGRATIVA - TCI
}

\begin{abstract}
INTEGRATIVE PRACTICES IN HEALTH CARE IN THE CONTEXT OF HIGH SCHOOL: THE EXPERIENCE OF INTEGRATIVE COMMUNITY THERAPY - TCI
\end{abstract}

\author{
Djailton Pereira da CUNHA ${ }^{1}$ \\ Marluce Tavares de OLIVEIRA ${ }^{2}$
}

RESUMO: Analisar as contribuições da TCI na abordagem de sofrimentos de estudantes em Escolas de Referência de Ensino Médio; Recife, Pernambuco. Pesquisa qualitativa, compreensivo-interpretativa, entre fevereiro/2018 a julho/2019. Desafios e Sentimentos; Estratégias de Superação e Aprendizados definidos como eixos temáticos da análise de conteúdo de Bardin, a partir das fichas de registro de TCI e anotações de campo. Realizados 33 encontros, com média de 13,5 alunos de 15 a 19 anos, de ambos sexos. Conflitos familiares, desempenho escolar e perspectivas de futuro, vinculados à tristeza, medo, raiva, incapacidade e solidão reforçam desafios da adolescência contemporânea, enfrentadas através de redes de apoio, ajuda profissional, empoderamento pessoal e atividades físicas e de lazer. Desafios iniciais foram substituídos pela ética da solidariedade nos processos de acolhimento, escuta afetiva e respeito à diversidade, sinalizando a TCI como estratégia de transformação de situações de risco para autonomia no âmbito escolar.

PALAVRAS-CHAVE: Cuidado. Práticas integrativas. Terapia comunitária integrativa (TCI). Adolescentes. Escola pública.

RESUMEN: Analizar las contribuciones de la TCI para lidiar con sufrimientos de estudiantes en Escuelas secundarias; Recife, Pernambuco. Investigación cualitativa, entre febrero/2018 y julio/2019. Desafios, sentimientos, estrategias de superación y aprendizajes, como ejes temáticos del análisis de contenido de Bardin, a partir de fichas y anotaciones de campo. 33 ruedas realizadas, promedio 13,5 estudiantes de 15-19 años de ambos sexos. Conflictos familiares, rendimiento escolar, perspectivas de futuro vinculados a tristeza, miedo, rabia, incapacidad y soledad, refuerzan los desafíos de la adolescencia contemporánea, que son enfrentadas a través de redes de apoyo, ayuda profesional, empoderamiento personal, actividades fisicas y recreación. Los desafios iniciales fueron reemplazados por solidaridad en

\footnotetext{
${ }^{1}$ Universidade de Pernambuco (UPE), Recife - PE - Brasil. Professor adjunto do Departamentos de Psicologia e do Departamento de Medicina. Doutorado em Educação (UFPE). ORCID: https://orcid.org/0000-0002-50247824.E-mail: djailtoncunha@uol.com.br

${ }^{2}$ Universidade de Pernambuco (UPE), Recife - PE - Brasil. Professora Adjunta aposentada. Doutorado em Saúde Materno Infantil (IMIP). ORCID: https://orcid.org/0000-0001-9725-1196. E-mail: marlucetavares.upe@gmail.com
} 
los procesos de acogida, escucha afectiva y respeto a la diversidad. Se señala la TCI como estrategia de transformación de situaciones de riesgo, para la autonomía en la Escuela.

PALABRAS CLAVE: Cuidado. Redes de apoyo. Terapia comunitaria integrativa (TCI). Adolescentes. Escuela pública.

ABSTRACT: Analyze the contributions of ICT in students suffering approach from Reference Schools of Secondary Education; Recife, Pernambuco. Qualitative, comprehensive-interpretive research, between February 2018 and July 2019. Challenges and Feelings; Overcoming and Strategies and Learning were defined as thematic axes of Bardin's content analysis, based on the ICT registration sheets and field notes. 33 meetings were held, with an average of 13.5 students aged 15 to 19, of both sexes. Family conflicts, school performance and future prospects, linked to sadness, fear, anger, incapacity and loneliness endorse the challenges of contemporary adolescence, faced through support networks, professional help, personal empowerment and physical and leisure activities. Initial challenges were replaced by the ethics of solidarity in welcoming processes, affective listening and respect for diversity, signaling ICT as a strategy for transforming risk situations for autonomy in the school environment.

KEYWORDS: Care. Integrative practices. Integrative community therapy (ICT). Teens. Public school.

\section{Introdução}

\section{Práticas integrativas de cuidado em saúde e processos formativos-educacionais: diálogos em construção}

Face à crise na área da saúde e bem-estar, pela exaustão do modelo de assistência calcado na medicalização e uso crescente de tecnologias; a implantação da Política Nacional de Práticas Integrativas e Complementares (PNPICS/MS) em 2008, busca a retomada das ações estratégicas constitutivas dos pressupostos e diretrizes do Sistema Único de Saúde, SUS, pela adoção de uma abordagem promotora de bem-estar, qualidade de vida, resistência e fator de saúde mental. Numa perspectiva mais abrangente, podemos pensar tais práticas como elementos-fundantes de processos de formação humana.

A escolha valorativa da proposta de trabalho, pelo espaço do ensino médio em escolas de referência da educação, teve como substrato a ideia de que as chamadas "crises de instabilidade" que podem se assestar em períodos de transição do ciclo vital de grupos populacionais, onde, os chamados "ritos de passagem" podem representar um risco adicional para a manutenção da saúde mental dos indivíduos envolvidos. Desta forma, a vivência e construção da própria identidade, da sexualidade, e exposição a situações de vulnerabilidade, 
como o uso de drogas e as diversas formas de violência, adquirem especial relevância na adolescência contemporânea (FERREIRA et al., 2018; OLIMPIO; MARCOS, 2015).

É nesta etapa de transição, onde se espera encontrar um papel proativo na profissionalização, autocuidado e capacidade de escolhas valorativas, com vistas ao pleno desenvolvimento da autonomia e potencialidades para o viver cotidiano. A aquisição de tais características não se faz de forma natural, mas são mediadas pelo viver social, consubstanciado na estruturação de contextos, os quais carreiam toda uma gama de estímulos, oportunidades e aberturas desiguais e não apenas diferentes. Integrar os adolescentes na condução da sua própria vida, através de processos participativos para o empoderamento dos mesmos, resulta na construção do protagonismo juvenil, sendo responsabilidade de toda a sociedade. $\mathrm{O}$ estabelecimento de canais de comunicação eficientes e vínculos de responsabilidade se constituem em etapas úteis para a formação plena do cidadão.

O presente trabalho surgiu alicerçado no encontro "tri-dimensional" dos pilares de sustentação da universidade (pesquisa, ensino e extensão), como uma tentativa de resposta à sociedade, pelos estudos desenvolvidos na formação em Terapia Comunitária Integrativa - TCI (BARRETO, 2008), e em pesquisas de doutorado (CUNHA, 2017; OLIVEIRA, 2011).

A TCI, instituída como PICS, através da Portaria GM 849/2017 (BRASIL, 2018) é um procedimento em grupo, que tem sua ação centrada no encontro de pessoas que sofrem ou vivenciam os efeitos do viver contemporâneo, seja nas comunidades ou em ambientes de estudo ou trabalho, na busca de acolhimento para situações de conflito, onde o cuidado é pensado como "uma atividade desenvolvida com a finalidade de aperfeiçoar o sujeito em sua relação com o outro" (FERREIRA et al., 2018, p. 58), na perspectiva de um processo de transformação de si e com o outro e ação no mundo, de educação para saúde, para a vida. Nesse sentido, o papel do cuidador, daquele que acolhe e cuida da dor alheia, é fundamental:

Ser cuidador, não é dizer ao outro o que ele tem que fazer, mas sim, lembrar ao outro quem ele é. Quando se lembra ao outro quem ele é, ele retoma seu ânimo, suas forças, seu rumo de vida. Essa é a função primordial do cuidador, lembrar quem o outro é, seja através de músicas, de danças, de massoterapia, de conversas, etc. (BARRETO, 2017, p. 75).

Buscamos com esse estudo, compreender a contribuição da TCI no acolhimento das inquietações e dores e no empoderamento de adolescentes de Escolas de Referência de Ensino Médio - EREM, do Recife, PE, com vistas à promoção do desenvolvimento humano. Isso implica em implementar processos de formação humana multidimensional, de forma a 
assegurar maior bem-estar existencial, melhoria das redes de relacionamentos, face aos desafios e impasses na sociedade contemporânea.

\section{Metodologia}

\section{Os caminhos de investigação das práticas de TCI em EREM de PE}

Os processos metodológicos tiveram por base, dados secundários - fichas de registro de rodas de TCI e anotações de reuniões de acompanhamento - produzidos na operacionalização de intervenção com práticas de cuidado no acolhimento de sofrimentos e dificuldades enfrentadas por adolescentes escolares do ensino médio. O cenário da investigação envolveu duas EREM de PE: Ginásio Pernambucano (EREM-GP) e Joaquim Nabuco (EREM-JN), através de parceria com o Espaço Família - Serviços Jurídicos e Terapêuticos, ONG, da qual fazem parte autores do presente trabalho. A imersão dos autores na operacionalização da proposta de intervenção, levada a cabo previamente nas escolas, permitiu a construção de uma memória da experiência, a partir da observação de campo, trazendo uma visão privilegiada para o uso de dados secundários, na medida em que recoloca a dimensão vivencial como importante elemento da análise. Trata-se, portanto, de uma pesquisa compreensivo-interpretativa de abordagem qualitativa, onde o pensar a ação se consolida enquanto prática educativa emancipatória. A definição da implantação da intervenção envolveu atividades desenvolvidas em 2 etapas:

1) Etapa preliminar - Sensibilização da comunidade escolar. Na qualidade de professores universitários na área de saúde e voluntários de ONG, em algumas comunidades, fomos sensibilizados pelas realidades presentes nas EREM em pauta. Ao exercitar um olhar e escuta qualificada, na observação de aulas e interrelações entre gestores, professores e alunos, evidenciou-se um certo "mal-estar" psico-emocional-social-existencial, que sinalizava a perda do sentido de estar ali, seja ensinando, seja aprendendo. As ações para viabilização da proposta contemplaram os objetivos propostos e a dinâmica singular de cada uma das escolas: contatos com a gestão; discussão com a comunidade escolar em seminário anual de avaliação pedagógica; realização de rodas de TCI com docentes e discentes e divulgação à comunidade escolar, para viabilização da participação dos alunos.

2) Trabalho de Campo - Rodas de partilha com TCI (BARRETO, 2008) com periodicidade semanal; duração média de 2 horas e seis etapas - acolhimento, escolha da inquietação/tema, contextualização, problematização, encerramento e apreciação. Esta última, apenas entre terapeutas, com vistas à reflexão dos processos de condução da atividade: aspectos 
que merecem ser repetidos e/ou necessitam aprimoramento, registro dos aprendizados sobre si e demais participantes e outras providências. Além das rodas de partilha, na EREM-JN foram realizadas de agosto/18 a dezembro/18, "Oficinas de Sentido", seguindo a abordagem Transpessoal estudada por Cunha (2017).

Do ponto de vista dos procedimentos éticos (BRASIL, 2012), por se tratar de um estudo com utilização de dados secundários, sem a identificação dos participantes da proposta de intervenção, os termos de consentimento livre e esclarecido são dispensados.

Os resultados dos encontros foram avaliados através da frequência das temáticas abordadas nas rodas, do empoderamento dos participantes e das falas da comunidade escolar. O material empírico apresentado foi produzido a partir dos relatos de observação de campo e dos relatórios de 33 rodas de partilhas realizadas, envolvendo apenas o público de adolescentes do ensino médio. O produto desse material foi discutido com base na análise de conteúdo proposta por Bardin (2005), que compreende: 1) pré-análise, 2) exploração do material e 3) tratamento dos resultados, inferência e interpretação. A última etapa desse processo consistiu no tratamento dos dados obtidos com a codificação-classificação-categorização, possibilitando com isso a compreensão e a interpretação dos resultados. Como destaca a autora, essa fase é dedicada a avaliação crítica e reflexiva, o que envolve intuição e razão simultaneamente. $\mathrm{O}$ percurso analítico subsidiou a construção de três grandes eixos temáticos: (1) Desafios e Sentimentos, (2) Estratégias de superação e (3) Aprendizados.

\section{Resultados}

\section{Contribuições da TCI para alunos das EREM de Pernambuco}

Foram realizadas 33 rodas de TCI, com uma média de 13,5 escolares beneficiários diretos por encontro, resultando em um total de 447 participações, em sua maioria do sexo feminino (54,6\%), com idades entre 15 a 19 anos e oriundos de periferias da capital e RM do Recife. A despeito desta homogeneidade aparente, carreiam estereótipos culturais diversos: enquanto os alunos do EREM-GP são vistos como pertencentes a uma certa elite intelectual de uma das escolas mais tradicionais do Estado, que no passado teve como alunos, políticos, empresários e profissionais liberais renomados; os alunos da EREM-JN são, predominantemente, da Comunidade do Coque, conhecida como morada da morte, face aos elevados índices de violência. A proposta de cuidado envolveu, no EREM-JN, alunos dos três anos do ensino médio, de forma equitativa, enquanto no EREM-GP, apenas os alunos do último ano do EM participaram do projeto. Com o intuito de compreender os elementos-componentes 
das narrativas dos sujeitos-integrantes do estudo, buscamos organizar e discutir cada categoria encontrada como meio para caracterizar as principais contribuições da TCI promovida pelas rodas de partilha.

\section{Desafios e Sentimentos}

As inquietações trazidas pelo grupo na etapa da escolha do tema apontam os desafios que adolescentes e jovens de periferia experimentam no seu dia-a-dia (FERREIRA et al., 2018; PRATTA; SANTOS, 2007). Conflitos interpessoais e outras formas de violência, baixa autoestima e questões relativas ao futuro e ao sentido da vida são elementos que compõe a paisagem mental e os temas apresentados pelos alunos, que possibilitam perceber a fase da adolescência como um processo de descoberta de potências latentes imersas em dúvidas, inseguranças, desconfiança e outras situações de risco para autonomia. Ao aprofundar a narrativa de suas inquietações e desafios, os adolescentes apresentaram sentimentos que refletiam e potencializavam tais experiências, caracterizando situações-problemas vivenciados pela juventude na contemporaneidade, emergindo no processo de fala-escuta vivenciados. As falas dos participantes estavam diretamente ligadas as seguintes dimensões:

(1) Pessoal/Individual - Para compreender tais inquietações, sob uma perspectiva de potência e competência, que se produz na diferença e na carência, recorremos a Ferreira et al. (2018), quando aponta que:

As adolescências periféricas inscrevem-se nos espaços de resistência a todas as formas de redução, abrem brechas nas estruturas dominantes que tomam as adolescências e juventudes como uma categoria substancial, a-histórica e capaz de responder a multiplicidade de modos de ser, não se limitando a uma forma predefinida que coloca a adolescência em um espaço patológico (p. 92).

Desse modo, cada inquietação (re)vela mais do que dor-sofrimento, aponta horizontes ocultos de resiliência, empoderamento e superação. Isso pode ser ilustrado em alguns temas apresentados pelos adolescentes nas rodas de partilha estudadas, possibilitando o (re)conhecimento de forças e estratégias de enfrentamento. São eles:

Incapacidade e insuficiência para resolver algo ou dizer não ao que não deseja/quer; Raiva de si mesmo; Arrependimento por decisões não ter tomadas; Vazio existencial; Frustração em relação aos sonhos; Dificuldade de confiar, de falar dos seus problemas; Rejeição e solidão nas relações amorosas e isolamento por não se sentir aceita; Insegurança diante da vida. [Desafios e Sentimentos - dados originais]. 
(2) Família - O papel do grupo familiar (PRATTA; SANTOS, 2007; COSTA et al., 2007), tem sido relatado como fundamental na constituição dos indivíduos, na determinação e na organização da personalidade e pela influência exercida sobre o comportamento individual de seus membros, sendo considerada responsável pelo processo de socialização primária das crianças e dos adolescentes. O ciclo de vida familiar com filhos adolescentes se apresenta como um período particularmente vulnerável para a trajetória familiar, na medida em que se caracteriza como uma fase de transição de um estado de dependência para o desabrochar para uma condição de autonomia pessoal - assunção do autocontrole em substituição à necessidade de controle externo. A esse respeito, Olimpio e Marcos (2015) destacam que nesta fase de vida o adolescente "[...] se esquiva dos modelos e do controle dos seus familiares tentando se desembaraçar deles. Nessa etapa, o adolescente parte ao encontro com o Outro, num movimento ambíguo em que ele se identifica e se opõe aos ideais da cultura" (OLIMPIO; MARCOS, 2015, p. 507-508).

Neste contexto, as inquietações elencadas nas rodas de partilha, como conflitos familiares e dificuldades no relacionamento com pais; situações de rupturas dos vínculos familiares (separação dos pais, perda de familiares), bem como um olhar de desaprovação crítica acerca de si e dos demais (ser um peso para família, hipocrisia dos pais, não ser aceita por opções sexuais) geraram desafios emocionais a serem ressignificados: revolta e ódio, inseguranças, medos, tristeza, solidão, angústia sem explicação e vontade de fugir de tudo.

(3) Escola - Relação com Pares e Perspectivas de futuro. Existem relatos de que a violência nas escolas - depredações, manifestação de comportamento hostil, falta de limites e desrespeito às autoridades, entre outras, esteja ligada aos níveis de autoestima dos alunos (MARRIEL et al., 2006), ou seja, a avaliação do valor ou importância que cada um faz de si próprio, referendada por pessoas significativas na sua formação, principalmente, pais, professores e amigos (FREIRE; TAVARES, 2011). As falas partilhadas nas rodas gravitaram em torno dos desafios enfrentados pelos adolescentes no âmbito pessoal e institucional.

a) violência patrimonial e estrutura da escola: raiva por material escolar quebrado e novo formato das bancas escolares; b) dificuldades comunicacionais em relação aos pares: não ter com quem compartilhar problemas, arrependimento pelo que foi falado, isolamento para evitar conflitos com amigos, ódio pelas pessoas não cuidarem da própria vida; c) medo do futuro: ansiedade pela pressão da escola, pela escolha da profissão e pelos novos desafios e os medos pela pressão do ENEM, de não conseguir emprego, de não alcançar o patamar desejado, de não conseguir um futuro legal, de não saber o que quer diante da vida adulta; d) imagem que os outros fazem de si: Desespero pelo julgamento dos outros, com relação ao que tem, e não ao que é. [Desafios e Sentimentos - dados originais]. 
A respeito desta última característica, uma inquietação eleita, para aprofundamento, por 34 dos presentes numa roda - vontade de fugir de tudo - deu lugar ao abandono do lugar da roda. No diálogo, com uma das terapeutas, hebiatra, referiu não "suportar" enfrentar o olhar das demais após o ocorrido, pois passava para todas a imagem de uma pessoa alegre, feliz e que o motivo pelo qual tentara o suicídio, vinculava-se ao fato de que a vida em família tornara-se insuportável, após o conhecimento da sua opção homossexual: “O que vão pensar de mim?”. O foco em perguntas que buscassem provocar uma reflexão sobre os motivos pelos quais tantas colegas haviam escolhido sua história, levou a elaboração de que "talvez passem o que passei", o que a fortaleceu o suficiente para retornar à sala, a tempo de ouvir histórias de superação e partilhar o que aprendera com a experiência, na fase do encerramento.

Eu sai porque tive vergonha de mostrar quem eu sou e a família que tenho. Porque achei que essas coisas só aconteciam comigo, mas quando ouvi que outros estão passando ou já passaram por isso e estão lutando para enfrentar, eu me senti aliviada e tive coragem de falar (M.E.B). [Desafios e Sentimentos - dados originais].

Para Olímpio e Marcos (2015), o papel da escola em oferecer aos alunos apoio e amparo, na adolescência, que é a fase de afrouxamento dos vínculos familiares, já ressaltado por Freud, no início do século passado, em resposta ao elevado número de suicídios de estudantes secundaristas na sua época.

Atos sintomáticos, presentes na anorexia, bulimia, toxicomania, automutilações, tentativas de suicídio, delinquência, entre outros, marcam o desamparo que pode colocar a vida do sujeito em risco. [...] $\mathrm{O}$ ato que o adolescente engendra é um dizer na tentativa de ser escutado (OLIMPIO; MARCOS, 2015, p. 508).

O convite do EREM-GP ao Espaço Família, para a realização das rodas de TCI, surgiu na busca de acolhimento para dar vazão aos conteúdos subjacentes aos sintomas disfuncionais no ambiente escolar, considerando ter chegado ao seu conhecimento cinco tentativas de suicídio entre adolescentes do segundo ano do ensino médio. A intervenção teve lugar no ano seguinte, disponível para todos alunos do último ano, oferecendo aos estudantes a oportunidade de uma fala-escuta sensível, para além do aparente.

(4) Direitos, Segurança e Cidadania - Deparar-se com o fenômeno sociocultural acarreta no enfrentar(-se) e implicar(-se) face aos diferentes contextos e situações do tecido social, como preconceitos (cor, raça, etnia, classe, credo, etc.), prostituição, condições de vida, transporte, lazer configuram outros modos de ser-estar no mundo para o adolescente (FERREIRA et al., 
2018). Nas rodas de partilha, encontramos temáticas que bem caracterizam essa perspectiva voltada para os aspectos socio-político-culturais:

Medo de passar fome pelo Comunismo, caso determinado candidato fosse eleito; Tristeza pelo analfabetismo político no momento atual do Brasil; Ansiedade no meio social, por não se sentir compreendida e aceita na sua opção sexual; Raiva por intolerância, preconceito; Medo da agressão e apreensão diante das condições de violência nos dias atuais [Desafios e Sentimentos - dados originais].

(5) Saúde - O repertório de inquietações apresentadas pelos alunos-participantes desse estudo, envolveu depressão, hiperatividade e pensamentos suicidas, ora como sentimentos experienciados, ora como ilustrações para estratégias de enfrentamentos adotadas. Além disso, estiveram presentes ao longo das demais etapas: Tristeza por ser bipolar; Medo de si mesmo e de ser bipolar. A mudança do perfil de adoecimento especialmente neuronal, cujas patologias psíquicas emergem e configuram um novo cenário de doenças no início do século (HAN, 2015), corrobora com a escassa referência a doenças orgânicas nas rodas de TCI: Medo de não se tornar atleta devido ao projétil que tem na perna; Tristeza pelo pé lesionado.

As inquietações elencadas das falas dos adolescentes participantes, encontram eco em relatos de estudantes equatorianos de cursos preparatórios para ingresso universitário e dos primeiros períodos de cursos superiores, descritos por Mey et al. (2016), onde questões como sofrimentos psíquicos pessoais e conflitos interpessoais, com predomínio daqueles de natureza familiar, assumiram posição de destaque. Chamou atenção a ausência de relatos acerca de inquietações referente ao uso/abuso de drogas, mesmo em se tratando de estudantes moradores de áreas consideradas de risco para tal situação. Costa et al. (2012), no tocante a drogas em área de risco, relataram que família, grupo social, escola, vida em área de risco e mídia aparecem nas falas dos adolescentes ora como aspectos de influência, ora como protetores; enquanto as redes de apoio social se destacam essencialmente como protetoras. Isso nos leva a pensar que para os alunos participantes desse trabalho, apresentar tais temas de forma direta, num ambiente escolar, ainda pode ser "mal visto", um "tabu" a ser refletido.

\section{Estratégias de superação}

Entre os benefícios identificados, emergiu da fala dos estudantes, estratégias de superação voltadas para empoderamento pessoal, apoio de redes de relacionamento, ajuda profissional e outras como escutar música, praticar exercícios físicos e ler/estudar, um novo olhar frente às dificuldades vivenciadas; contribuição para o debate de modos de comunicação 
não violenta e o respeito às diversidades; a constatação de que não estão sós em suas jornadas pessoais e a reflexão sobre suas potencialidades para enfrentamento das mesmas. As narrativas dos participantes destacam as principais estratégias adotadas relacionadas à:

(1) Fortalecimento/Empoderamento pessoal/Autocuidado - As ações voltadas para essa categoria foram as mais compartilhadas pelos adolescentes participantes das rodas. Esse resultado corrobora ao estudo apresentado por Barreto (2008), quando aponta um índice de $31,37 \%$ de estratégias de superação partilhadas, voltadas ao empoderamento pessoal, na amostragem de 10.005 terapias realizadas. Aspectos como focar em si e nos seus objetivos, autocuidado e autoconhecimento, destacados pelos alunos, foram sistematizados como como elementos-chave das principais estratégias de superação apresentadas.

a) Focar em si, buscando sua força: Procurar algo novo para se sentir feliz; Transformar as críticas em sim, eu posso; avaliação das qualidades pessoais; assumir as responsabilidades; b) Focar nos objetivos: Se adaptar às situações novas; Tirar o foco do problema; Planejar ações, focando no estudo; Fazer coisas que gosta. c) Autoconhecimento: Aprender que sofrimento gera experiência; compreender que nas "coisas ruins" têm algo a aprender; Saber que dei o melhor de mim; Autoconfiança, não gerando expectativas; valorizar o que tenho, o que sou. [estratégias - dados originais].

Tais ações reforçam os argumentos de que os adolescentes de periferias têm uma potência que impele a reinvenção de si com a produção de uma multiplicidade de sentidos e de ações que promovem o desenvolvimento de competências frente aos desafios e carências do processo sócio-histórico envolvido (FERREIRA et al., 2018).

(2) Buscar redes solidárias - A participação nas rodas de TCI se mostrou como uma potente referência para a construção e fortalecimento de redes de apoio solidárias, seja experenciando o exercício do diálogo com familiares e amigos, seja pela identificação do apoio no ambiente escolar, ampliando o horizonte de possibilidades de vínculos mais saudáveis na construção do espaço pessoal, quando do relato de estratégias de superação das inquietações apresentadas, incluindo o próprio espaço da roda de partilha:

Roda de conversa com quem tem o problema; Ficar na escola buscando conversar com os amigos para descontrair; Investir em novas amizades, para o caso de se decepcionar; Criar laços afetivos para vencer as dificuldades; procurar e ficar próximo das pessoas; Apoio de amigos e de professor; Conversar com familiares e amigos; Confiar nas pessoas, mesmo que elas errem e seguir em frente; exercitar o perdão; procurar grupos de autoajuda. [estratégias - dados originais].

Para Rossi et al. (2019, p. 216) as demandas em saúde mental de adolescentes usuários de serviços de assistência - CAPSi - vinculam-se a "sentimentos intensos de angústia, tristeza 
e desvalia, ideação e tentativa de suicídio - vivenciados como um problema individual", que denota falha da rede de apoio social (FERNANDES; MATSUKURA, 2015) no acolhimento, atuando de forma preventiva nas situações de crise, que corroboram para o isolamento e acirramento das situações de risco para o projeto emancipatório juvenil.

(3) Buscar ajuda religiosa ou espiritual - De acordo com Barreto (2008, p. 344), "O recurso ao mundo espiritual é uma das formas mais frequentes de se nutrir a esperança na luta contra as adversidades”. Uma concepção de espiritualidade integral "[...] revela o papel novo da religião e os estágios de desenvolvimento da espiritualidade" (FERREIRA et al., 2018, p. 160). Na linguagem dos adolescentes, a procura-encontro dessas instâncias perpassa por uma experiência existencial, "incorporando" o transcendente ao imanente, de modo a obter o apoio necessário para a superação dos desafios que enfrentam:

Procurar se identificar como cristão para superar as situações adversas; Ter experiências novas com a religiosidade; Participar das atividades na igreja e no NEIMFA (Reiki, Roda de cura); Busca da espiritualidade (voltar a frequentar a igreja; buscar Jesus); Fé em Deus (é um momento e vai passar); Obter o apoio da religião, da igreja [estratégias - dados originais].

(4) Cuidar e se relacionar melhor com a família/comunidade - Estudo com adolescentes e jovens, envolvendo aspectos das relações interpessoais, aponta o apoio de amigos e de familiares como promotores de elevados índices de confiança e expectativa de oferecimento da contribuição necessária (ROSSI et al., 2019). Entre os alunos participantes, a superação das dificuldades enfrentadas no cotidiano de suas vidas, além do enfoque familiar mais geral, há referência aos avós (OLIVEIRA; PINHO, 2013) e irmãos mais velhos:

Respeito e reconhecimento dos pais às suas dificuldades; conversando com o pai e a avó; Avó acolheu sua dor; desabafando com a prima e irmã 2 anos mais velha; Ouvir e conversar, tentando entender os dois lados; Procurava agradar um pouco a família, no que podia; Sair do recinto da confusão e de perto de quem estar causando estresse [estratégias - dados originais].

(5) Buscar ajuda profissional - O papel ocupado pelo trabalhador de saúde mental no dia a dia de jovens aponta que "[...] a qualidade das relações nas práticas profissionais nos equipamentos estratégicos de atenção à saúde mental infanto-juvenil” (ROSSI et al., 2019, p. 6) como fator de destaque nas experiências face ao cuidado à saúde mental. Nesse contexto, “é possível que a rede de suporte social composta em sua maioria por profissionais do CAPSi, reforce a compreensão de que esse equipamento é um dos raros, senão únicos, contextos de inserção desses jovens” (FERNANDES; MATSUKURA, 2015, p. 222). 
As estratégias de compartilhadas pelos adolescentes reforçam esse argumento, quando apontam a busca de ajuda de serviços de saúde geral e mental (psiquiatra, psicólogo, CAPES); apoio da gestão escola e práticas de Meditação. Tais estratégias ilustram também os argumentos de Barreto (2008), quando afirma que "o apelo às instituições sociais reflete certa consciência das responsabilidades, deveres e direitos dos cidadãos" (BARRETO, 2008, p. 346).

(6) Busca de recursos da cultura e tecnologia e ações de cidadania - mostram uma diversidade onde coexistem práticas modernas e antigas, centradas em estratégias:

a) Culturais e expressão artística - participação em projetos sociais e trabalhos voluntários, grupos de dança, teatro ler, escrever, desenhar ouvir música, filmes e vídeos, dançar b) Atividade fisica e caseiras - judô; boxe; futebol, brincar com animal de estimação (cachorro e gato); c) Autocuidado: cuidar das unhas, cabelos, sobrancelha; d) tecnológicas - usar aplicativos do celular, seguir influenciadores digitais, youtubers; jogos eletrônicos, buscar conhecimento, pesquisa sobre formação; e) Desenvolvimento da Espiritualidade - Escutar mantras, contemplar a natureza, Aceitar a dinâmica da vida e; f) Atividades voluntárias - ajudar as pessoas, passear com sobrinho; ações sociais [estratégias - dados originais].

(7) Participar da Terapia Comunitária Integrativa - Os grupos de autoajuda como a TCI são recursos comunitários de grande potência. Para Barreto (2008, p. 349), "Estes grupos tornam-se UTIS existenciais. Eles são procurados a todo momento. São grupos acessíveis, constituídos por pessoas de grande disponibilidade e determinação". Na fala dos adolescentes, "Participar das rodas de TCI da escola: me sinto muito melhor quando falo".

De forma similar, considerando a interface entre dificuldades estudantis e condições de saúde e trabalho de docentes e gestores, um maior conhecimento acerca de situações de risco pode potencializar a busca de estratégias para minimizar os efeitos indiretos desse evento sobre a população docente (situações de stress), bem como de medidas preventivas e/ou outras intervenções sobre o problema (maior resiliência a situações conflituosas no âmbito escolar reforçada pelo aumento da participação em redes/grupos sociais de apoio).

\section{Aprendizados}

Comungamos com Barreto (2008, p. 355), quando aponta que "na leitura geral dos depoimentos espontâneos e das partilhas, no final da terapia, notamos a predominância marcante de depoimentos referentes ao aprendizado". Para o referido autor, isso demonstra o alinhamento da TCI frente a um de seus pilares teórico que é a pedagogia de Paulo Freire.

A pequena parcela de estudantes participantes nos encontros, em comparação com o universo discente das escolas, trouxe à tona paradoxos importantes: a contribuição para o debate 
de formas de comunicação não violenta e o respeito às diversidades, tônica reforçada entre os participantes das rodas de partilha, contrastaram com relatos relativos à manutenção de conflitos interpessoais e outras formas de violência escolar, que sinalizam para a manutenção de situações de risco para a integridade da comunidade estudantil.

A participação nas rodas, contribuiu, na fala dos estudantes, para formação de redes de apoio. Além disso, possibilitou uma discussão do lugar da família, da escola, da comunidade frente ao processo formativo-educacional e face à saúde (completo bem-estar físico, mental, social e espiritual) dos adolescentes na atualidade. Para os alunos envolvidos nessas atividades, as rodas promoveram diferentes tipos de aprendizados, sentimentos, experiências:

Aprendi que existem várias possibilidades de superação e estratégias para lidar com a tristeza, a perda e o vazio; Muito bom, porque as vezes a gente pensa que o problema é só com a gente; Gratidão pela oportunidade de estar compartilhando coisas que não se fala no dia a dia; Alívio: tirei o peso que me incomodava; Eu sou o maior responsável por mim, Sentimento de liberdade, reflexão, satisfação, felicidade; Criando confiança no Grupo da TCI, Amizade compartilhada e a dar valor a quem merece; Esperança que a roda de TCI funcione como enzima, ou seja, acelere o processo de saída do sofrimento; Palavra-chave: autoaceitação [Aprendizados - dados originais].

Nesse sentido, entendemos que os principais aprendizados promovidos a partir das rodas contribuíram para um processo de educação para saúde, de formação humana, que faz despertar e vivenciar a dádiva, o "DOM" (MAUSS, 2012), o dar, o receber e o retribuir. Nas rodas de partilha da TCI, a dádiva, implica em "dar" (proporcionar) um espaço de fala e escuta afetiva, receber "estratégias de superação" e retribuir com aprendizados e ações no mundo de forma individual e coletiva. Nesse contexto, a dádiva pode ser encontrada na família, nas relações sociais, na educação, no trabalho, na política, na economia, nas artes, em tudo que existe. Podemos pensar assim, a dádiva como a chama que ilumina e aquece as partilhas nas rodas e porque não dizer nas "tramas" da vida.

\section{Considerações finais}

Percebeu-se a importância da TCI na promoção de bem-estar e saúde para os jovensalunos das escolas públicas investigadas, considerando-se a dimensão comunitária da prática. A despeito de características típicas da fase da adolescência, relacionadas à timidez, vergonha, rebeldia e irreverência, percebidas nos encontros, o aumento da participação dos alunos na partilha de suas inquietações e estratégias de superação se apresentaram de forma crescente. 
Os desafios iniciais foram paulatinamente substituídos pela ética da solidariedade nos processos de acolhimento, escuta afetiva e respeito à diversidade, constitutivo do arcabouço teórico-metodológico da Terapia Comunitária Integrativa - TCI. Nesse sentido, constatamos as contribuições da terapia comunitária integrativa frente as mudanças de comportamentos de alunos participantes desse estudo.

As temáticas discutidas nas rodas de partilha também revelaram como as questões atuais da sociedade vêm produzindo inquietações de diferentes dimensões, o que nos permitiu problematizar falas, conceitos, paradigmas, construindo-desconstruindo "lugares e instâncias" sob a perspectiva da terapia comunitária integrativa. Desse modo, a TCI destaca-se como uma estratégia de superação para aplicação no âmbito escolar e se consolida como uma abordagem que contribui para a comunidade de forma diferenciada na atualidade.

Assim, o recurso dos encontros de partilha com a TCI como uma prática de cuidado integrativo se consolida como uma proposta de contribuição para a melhoria do processo de bem-estar e das relações dentro da escola (empatia com os pares) e como intervenção no(s) mundo(s) dos participantes, como agente de TRANSformAÇÃO no campo educacional, promovendo aspectos de saúde mental.

\section{REFERÊNCIAS}

BARDIN, L. Análise de conteúdo. Ed. rev. e atualizada. Lisboa: Edições 70, 281 p., 2005.

BARRETO, A. P. Terapia comunitária: passo a passo. 4. ed. rev. ampl. Fortaleza: Gráfica LCR, 408 p., 2008.

BARRETO, A. P. Cuidadando do cuidador: Técnicas e vivências para o resgate da autoestima. Fortaleza: Gráfica LCR, 228 p., 2017.

BRASIL. Ministério da Saúde. Conselho Nacional de Saúde. Resolução n. 466, de 12 de dezembro de 2012. Dispõe sobre diretrizes e normas regulamentadoras de pesquisas envolvendo seres humanos. Brasília, 12 dez. 2012. Disponível em:

https://bvsms.saude.gov.br/bvs/saudelegis/cns/2013/res0466_12_12_2012.html. Acesso em: 16 nov. 2019.

BRASIL. Ministério da Saúde. Secretaria de Atenção à Saúde. Departamento de Atenção Básica. Manual de implantação de serviços de práticas integrativas e complementares no SUS. Brasília: Ministério da Saúde, 56 p., 2018.

COSTA, A. et al. Drogas em áreas de risco: o que dizem os jovens. Physis, Rio de Janeiro, v. 22, n. 2, p. 803-819, jun. 2012. Disponível em: http://www.scielo.br/scielo.php?script=sci_arttext\&pid=S0103$73312012000200021 \& 1 n g=$ en\&nrm=iso. Acesso em: 15 fev. 2020. 
CUNHA, D. P. Fundamentos multiparadigmáticos da formação humana: contribuições dos paradigmas transpessoal, intercultural e da espiritualidade para a educação no Brasil e na França. Orientadores: Aurino Lima Ferreira (UFPE) Nadja Acioly Régnier (LYON2). 2017. 416 f. Tese (Doutorado em Educação) - Universidade Federal de Pernambuco e Université Lumère Lyon 2, Recife/Lyon, 2017.

FERNANDES, A. D. S. A.; MATSUKURA, T. S. Adolescentes no CAPSi: relações sociais e contextos de inserção. Revista de Terapia Ocupacional da Universidade de São Paulo, v. 26, n. 2, p. 216-224, maio/ago. 2015.

FERREIRA, A. L. et al. As adolescências periféricas: uma pesquisa-ação integral/ transpessoal. 1. ed. Curitiba: Appris, 181 p., 2018.

FREIRE, T.; TAVARES, D. Influência da autoestima, da regulação emocional e do gênero no bem-estar subjetivo e psicológico de adolescentes. Rev. psiquiatr. clín., São Paulo, v. 38, n. 5, p. 184-188, 2011. Disponível em:

http://www.scielo.br/scielo.php?script=sci_arttext\&pid=S0101-

60832011000500003\&lng=en\&nrm=iso. Acesso em: 15 fev. 2020.

HAN, B. C. Sociedade do cansaço. Petrópolis: Vozes, 80 p., 2015.

MARRIEL, L. C. et al. Violência escolar e auto-estima de adolescentes. Cad. Pesqui., São Paulo, v. 36, n. 127, p. 35-50, abr. 2006. Disponível em:

http://www.scielo.br/scielo.php?script=sci arttext\&pid=S0100-

$15742006000100003 \& \operatorname{lng}=$ en\&nrm=iso. Acesso em: 15 jan. 2020.

MAUSS, M. Essai sur le don: forme et raison de l'échange dans les sociétés archaïques. 2. ed. Paris: Presses universitaires de France, DL, 248 p., 2012.

MEY, R. G. V et al. Ruedas Vinculantes como espacion de inclusion en el contexto universitario: la experiencia de la Universidad Estatal Amazónica, Puyo, Pastaza, Ecuador. Temas em Educação e Saúde, v. 12, n. 1, p. 97-107, jan./jun. 2016. Disponível em: https://periodicos.fclar.unesp.br/tes/article/view/9816. Acesso em 12 dez 2019.

OLIMPIO, E.; MARCOS, C. M. A escola e o adolescente hoje: considerações a partir da psicanálise. Psicol. rev., Belo Horizonte, v. 21, n. 3, p. 498-512, set. 2015. Disponível em: http://pepsic.bvsalud.org/scielo.php?script=sci_arttext\&pid=S1677-

11682015000300006\&lng=pt\&nrm=iso. Acesso em: 05 fev. 2020.

OLIVEIRA, A. R. V.; PINHO, D. L. M. Relações entre avós e seus netos adolescentes: uma revisão integrativa. Rev. bras. geriatr. gerontol., Rio de Janeiro, v. 16, n. 3, p. 633-642, set. 2013. Disponível em: http://www.scielo.br/scielo.php?script=sci_arttext\&pid=S180998232013000300019\&lng=en\&nrm=iso. Acesso em: 17 jan. 2020.

OLIVEIRA, M. T. Cuidar de si e do outro: análise de implantação de programa educativovivencial para atuação na violência intrafamiliar no nordeste brasileiro. 2011. Tese.

(Doutorado em Saúde Materno Infantil) - Instituto de Medicina Integral Professor Fernando Figueira, Recife, 2011. 
PRATTA, E. M. M.; SANTOS, M. A. Família e adolescência: a influência do contexto familiar no desenvolvimento psicológico de seus membros. Psicol. estud., Maringá, v. 12, n. 2, p. 247-256, ago. 2007. Disponível em:

http://www.scielo.br/scielo.php?script=sci_arttext\&pid=S1413-

$73722007000200005 \& 1 n g=e n \& n r m=$ iso. Acesso em: 25jan. 2020.

ROSSI, L. M. et al. Crise e saúde mental na adolescência: a história sob a ótica de quem vive. Cad. Saúde Pública, Rio de Janeiro, v. 35, n. 3, 2019. Disponível em:

http://www.scielo.br/scielo.php?script=sci_arttext\&pid=S0102-

$311 \mathrm{X} 2019000305004 \& \operatorname{lng}=\mathrm{en} \& \mathrm{nrm}=$ iso. Acesso em: 10 fev. 2020.

\section{Como referenciar este artigo}

CUNHA, D. P. da; OLIVEIRA, M. T. de. Práticas integrativas de cuidado em saúde no contexto do Ensino Médio: a experiencia da Terapia Comunitaria Integrativa - TCI. Temas em Educ. e Saúde, Araraquara, v. 16, n. esp. 1, p. 311-326, set., 2020. e-ISSN 2526-3471. DOI: https://doi.org/10.26673/tes.v16iesp.1.14311

Submetido em: 20/05/2020

Revisões requeridas: $30 / 05 / 2020$

Aprovado em: 25/08/2020

Publicado em: 30/09/2020 